\title{
Anticarbamazepine antibody induced by carbamazepine in a patient with severe serum sickness
}

\author{
Nozomi Hosoda, Wataru Sunaoshi, Hiroyuki Shirai, Yuki Bando, Hisao Miura, \\ Muneo Igarashi
}

\begin{abstract}
Anticarbamazepine antibody was detected in a patient who had clinical signs of serum sickness induced by carbamazepine. Skin rash, fever, oedema, and lymphadenopathy are classic signs of severe adverse reaction, but although immunological hypersensitivity is thought to be a contributory factor, the presence of anticarbamazepine antibody has not previously been reported to our knowledge.
\end{abstract}

Carbamazepine is widely used in the treatment of various forms of epileptic disorders. ${ }^{12}$ Although different side effects have been reported, skin rash is the most common adverse reaction. Exfoliative dermatitis, urticaria, toxic epidermal necrolysis, Stevens-Johnson syndrome, and a reaction similar to systemic lupus erythematosus have been reported. ${ }^{2}{ }^{3}$ In some cases the skin rash is part of a severe illness affecting several organs, and immunological hypersensitivity is thought to contribute to the skin reaction. ${ }^{3} 4$ So far, however, we know of no report of the presence of anticarbamazepine antibody in any patient with severe skin reactions.

We present a patient with the typical clinical manifestations of serum sickness, fever, eruption with oedema (particularly around the face and neck), and lymphadenopathy. The laboratory findings showed a decrease in complement $\mathrm{C} 4$ and an increase in C3a and C4a activity. Anticarbamazepine antibody was detected in the serum using an enzyme linked immunosorbent assay (ELISA).

\section{Methods}

$\mathrm{BALB} / \mathrm{C}$ mice were given carbamazepine ( $1 \mathrm{~g} / \mathrm{kg}$ ) orally, and bled six hours later. The serum was used as the antigen.

The anticarbamazepine antibody of serum from the patient was analysed by ELISA, a procedure that has been described elsewhere. ${ }^{5}$ Briefly, the mouse serum diluted $(1: 100)$ with $10 \mathrm{mM}$ carbonate buffer was added to 96 well polyvinylchloride microtitre plates, and left for two hours at room temperature. The nonbinding sites were blocked with phosphate buffered saline containing $0.05 \%$ Tween 20 and $2 \%$ ovalbumin. Diluted human serum was added to the wells and incubated for one hour at $4^{\circ} \mathrm{C}$. After three washings, $100 \mu \mathrm{l}$ of appropriately diluted horseradish peroxidase conjugated goat antimouse Ig antiserum was added to each well. The plates were then incubated for one hour at $4^{\circ} \mathrm{C}$ and washed three times, and
$200 \mu \mathrm{l}$ of freshly prepared substrate solution containing $0.05 \%$ o-phenylendiamine and $0.0075 \%$ hydrogen peroxide in McIlvain buffer, $\mathrm{pH} 6{ }^{\circ} 0$, was added to each well. After 30 minutes of incubation at room temperature, absorbance was read at $405 \mathrm{~nm}$ with a Titertek Multiskan plate reader.

\section{Case report}

An 8 year old girl was admitted with fever and skin rash. Thirty seven days before admission carbamazepine $200 \mathrm{mg}(10 \mathrm{mg} / \mathrm{kg})$ had been prescribed because of a complex partial seizure. Twenty seven days before admission the first skin rash had appeared on her cheeks, but this disappeared within a few days. Twenty three days before admission, the dose of carbamazepine had been increased to $300 \mathrm{mg}$. The day before admission she had again developed maculopapular erythema on her face and neck, this time accompanied by fever. Her past history and family history were not helpful. On examination she had maculopapular erythema on her face, neck, and trunk, and her body temperature was $40^{\circ} \mathrm{C}$. Several bilateral cervical lymph nodes were enlarged to less than $2 \mathrm{~cm}$ in diameter and the liver was also enlarged. Laboratory findings on admission included aspartate aminotransferase activity $108 \mathrm{U} / 1$, alanine aminotransferase activity $107 \mathrm{U} / 1, \mathrm{C} 3$ $1.29 \mathrm{~g} / \mathrm{l}, \mathrm{C} 4384 \mathrm{mg} / \mathrm{l}$; white blood cell count, haemoglobin concentration, and platelet count were normal. Carbamazepine had been discontinued because of suspected hypersensitivity, but the high fever and skin rash persisted. A week later the facial oedema was so bad that she could not open her eyes and she had developed a productive cough. Crackles could be heard in her chest and an $x$ ray film showed mild bronchopneumonia in the right middle lobe. She also had watery diarrhoea several times a day.

The pneumonia and the diarrhoea resolved within a few days without any special treatment, and the fever and skin rash subsided on the 15th day in hospital. Cultures of throat swabs, blood, and urine grew no pathogens. Antistreptolysin titre and Paul-Bunnell test were negative, as were other titres, including cytomegalovirus, Epstein-Barr virus, measles, rubella, and mycoplasma. Immunological findings on the 24th day in hospital were as follows: C3 $1.32 \mathrm{~g} / \mathrm{l}, \mathrm{C} 4$ $114 \mathrm{mg} / \mathrm{l}, \mathrm{C} 3 \mathrm{a} 1329 \mathrm{ng} / \mathrm{ml}$, and C4a $827 \mathrm{ng} / \mathrm{ml}$.

On the 26th hospital day, a patch test was done with carbamazepine, and with cephazolin as the negative control. An area of erythema with induration $1 \mathrm{~cm}$ in diameter was detected against carbamazepine, but there was no skin 


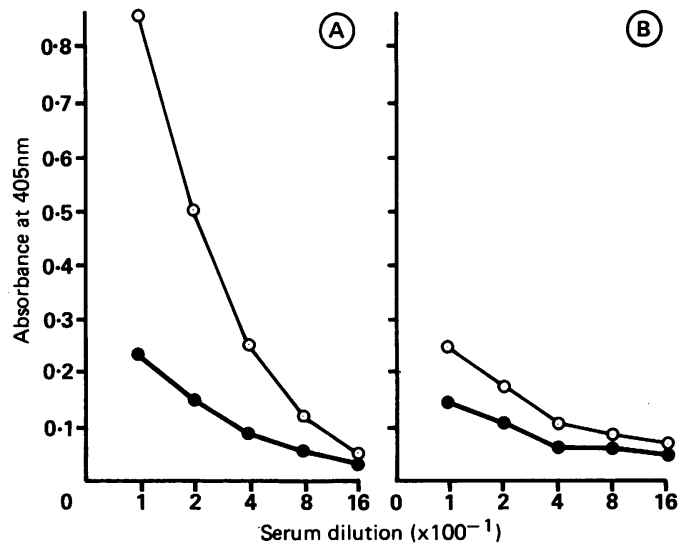

Titration of patient's serum $(\mathrm{O}-\mathrm{O})$ and normal human pooled serum (- ) against mouse serum containing carbamazepine $(A)$ and normal mouse serum $(B)$.

reaction against cephazolin. The results of ELISA titration of the patient's serum against carbamazepine are shown in the figure. The antibody titre of the patient's serum (on the 14th hospital day) against carbamazepine was significantly higher than against normal mouse serum. This showed that the antibody activity was carbamazepine specific because the patient's serum did not bind to normal mouse serum that was used as the negative control. The antibody activity of the patient's serum against normal mouse serum was slightly higher than that of normal pooled human serum. This activity was the result of antigen non-specific binding, because the patient's immunoglobulin concentration was about three times higher than that of normal human serum.

\section{Discussion}

Adverse reactions to drugs are common, and various mechanisms are responsible for most non-immunological drug reactions. True immunological reactions probably account for at most a quarter of the overall total of adverse drug reactions. ${ }^{678}$ Most drugs are simple chemicals with molecular weights of less than 1000 , and these are rarely immunogenic. Substances of low molecular weight may act as haptens, however, and became immunogenic after covalent chemical binding with tissue or plasma proteins to form drug-protein conjugates. ${ }^{8}$ In general, only drugs (or their degradation products or metabolites) with sufficient chemical reactivity to bind irreversibly to proteins are capable of inducing hypersensitivity reactions. After initial exposure to the drug, potentially allergic subjects have a latent period before the onset of the hypersensitivity reaction. During this seven to 10 day (up to three week) period, the drugprotein complex stimulates production of a sufficient number of activated immune effector cells and antibodies to cause the allergic reaction. ${ }^{68}$ It is rational to attribute the skin rash induced by carbamazepine to an immunological disorder, because $80 \%$ of carbamazepine can bind to protein ${ }^{10}$ and the skin rash does not appear for seven days. ${ }^{1}$

We have described a patient who showed the classic clinical picture of serum sickness. ${ }^{7}$ Carbamazepine specific delayed type hypersensitivity was detected by patch test, and carbamazepine specific antibody was also detected using an ELISA. These findings showed that carbamazepine specific $T$ cells and $B$ cells in the patient had been stimulated and proliferated into sufficient numbers of effector cells. Anaphylatoxins were increased and complement was depressed, suggesting that complement was activated by immune complexes. From the clinical picture and the laboratory findings we deduced that this case was compatible with serum sickness caused by massive amounts of carbamazepine antibody immune complexes. The extensive expansion of the clone size of anticarbamazepine cells could be attributed to the prolonged carbamazepine sensitisation. Usually such prolonged sensitisation would not happen, because carbamazepine is discontinued as soon as the skin rash appears. The evidence presented by this case suggests that most cases of carbamazepine induced skin rash might be the result of mild serum sickness.

Another question is: why are so few people allergic to carbamazepine? We used mouse serum as the antigen, which was obtained by bleeding from mice that had been given a large amount of carbamazepine. Though large numbers of immune complexes were predicted from the clinical picture and laboratory findings, few haptenic epitopes appeared in the mouse serum because the anticarbamazepine titre was low. This observation suggests that haptenic epitopes formed from carbamazepine metabolites appear in only a few patients who suffer from the immunological hypersensitivity induced by carbamazepine. To verify this possibility, further analysis will be required.

Gamstop I. Treatment with carbamazepine: children. Ad Neurol 1975;11:237-46.

Sillanpää M. Carbamazepine. Pharmacology and clinica uses. Acta Neurol Scand 1981;64(suppl 88):9-202.

3 Robert DL, Marks R. Skin reactions to carbamazepine. Arch Dermatol 1981;117:273-5.

4 Permin H, Sestoft L. Deposits of plasma proteins in the skin during treatment with carbamazepine and diphenylhydantoin. Acta Med Scand 1977;202:113-7.

5 Igarashi M, Kashiwagi N, Ferrone S. Serological and structural heterogeneity of HLA-DR and DQ antigens in HLA-DR4 homozygous B lymphoid cells. Kitasato Med 1987;17:194-204.

6 Kenneth PM. Clinical spectrum of allergic and pseudo allergic drug reactions. F Allergy Clin Immunol 1984;74:558-66.

7 Elliot FE. Allergic disorders. In: Behrman RE, Vaughan VC, eds. Nelson textbook of pediatrics. 13th Ed. Philadelphia: WB Saunders, 1987:480-513.

8 Patterson R, Anderson J. Allergic reactions to drugs and biologic agents. $\mathcal{F A M A}$ 1982;248:2637-45.

9 Chesham J, Davies GE. The role of metabolism in the immunogenicity of drugs: production of antibodies to horseradish peroxidase generated conjugate paracetamol Clin Exp Immunol 1985;61:224-31.

10 Morselli PL, Frigerio A. Metabolism and pharmacokinetics of carbamazepine. Drug Metab Rev 1975;4:97-113. 